\title{
Preparation of Highly Porous PAN-LATP Membranes as Separators for Lithium Ion Batteries
}

\author{
Jagdeep Mohanta ${ }^{1} \oplus$, O Hyeon Kwon ${ }^{2}{ }^{\oplus}$, Jong Hyeok Choi ${ }^{1}$, Yeo-Myeong Yun ${ }^{3}$, \\ Jae-Kwang Kim ${ }^{2, *}$ and Sang Mun Jeong ${ }^{1, *}$ \\ 1 Department of Chemical Engineering, Chungbuk National University,1 Chungdae-ro, Seowon-gu, Cheongju, \\ Chungbuk 28644, Korea; jagdeepmohanta@gmail.com (J.M.); qweaq1@naver.com (J.H.C.) \\ 2 Department of Solar \& Energy Engineering, Cheongju University, Cheongju, Chungbuk 28503, Korea; \\ ohhyeon2940@naver.com \\ 3 Department of Environmental Engineering, Chungbuk National University, 1 Chungdae-ro, Seowon-gu, \\ Cheongju, Chungbuk 28644, Korea; ymyun@cbnu.ac.kr \\ * Correspondence: jaekwang@cju.ac.kr (J.-K.K.); smjeong@chungbuk.ac.kr (S.M.J.)
}

Received: 26 September 2019; Accepted: 5 November 2019; Published: 7 November 2019

check for updates

\begin{abstract}
Separators are a vital component to ensure the safety of lithium-ion batteries. However, the commercial separators employed in lithium ion batteries are inefficient due to their low porosity. In the present study, a simple electrospinning technique is adopted to prepare highly porous polyacrylonitrile (PAN)-based membranes with a higher concentration of lithium aluminum titanium phosphate (LATP) ceramic particles, as a viable alternative to the commercialized separators used in lithium ion batteries. The effect of the LATP particles on the morphology of the porous membranes is demonstrated through Field emission scattering electron microscopy. X-ray diffraction and Fourier transform infrared spectra studies suitably demonstrate the mixing of PAN and LATP particles in the polymer matrix. PAN with $30 \mathrm{wt} \%$ LATP (P-L30) exhibits an enhanced porosity of $90 \%$ and is more thermally stable, with the highest electrolyte uptake among all the prepared membranes. Due to better electrolyte uptake, the P-L30 membrane demonstrates an improved ionic conductivity of $1.7 \mathrm{mS} / \mathrm{cm}$. A coin cell prepared with a P-L30 membrane and a LiFePO4 cathode demonstrates the highest discharge capacity of $158 \mathrm{mAh} / \mathrm{g}$ at $0.5 \mathrm{C}$ rate. The coin cell with the P-L30 membrane also displays good cycling stability by retaining $87 \%$ of the initial discharge capacity after 200 cycles of charging and discharging at $0.5 \mathrm{C}$ rate.
\end{abstract}

Keywords: PAN; LATP; electrospinning; separator; lithium ion battery; electrochemical characteristics

\section{Introduction}

A negligible memory effect, superior energy density, long cycle life, and environmental friendliness are some of the important characteristics that have allowed lithium ion batteries to dominate the commercial secondary battery market over the last three decades. Owing to their incredible advantages, lithium ion batteries are employed in various fields from smart phones to large electric vehicles [1-9]. In general, electrodes (i.e., anode and cathode), electrolytes, and separators constitute a lithium ion battery. Among these, the separator is an intrinsic component, as the safety of the lithium ion battery relies on its properties. The separator is the component that keeps the two electrodes apart, as their contact may lead to the battery short-circuiting. Apart from this, the separator is very valuable in terms of assisting ion transportation during both charging and discharging of the lithium ion battery [10-16]. Enhanced porosity, good electrolyte uptake, and better thermal stability are some of the essential features that help polymer membranes qualify as a competent separator for lithium ion batteries [17]. There are many methods for fabricating separators for lithium ion batteries, such as solvent casting, 
non-solvent-induced phase separation, electrospinning, the dry and wet method, and thermally induced phase separation. Of these, electrospinning is the most favorable technique for preparing separators due to its simple process and its ability to generate highly porous polymer membranes [18].

Until now, the commercial separator primarily employed in large-scale battery production has consisted of polyethylene and/or polypropylene because of the benefits these materials have when used as a separator, such as their economical cost, high electrochemical sturdiness, superior mechanical strength, and inbuilt shutdown feature, which prevent small functions in the case of increased temperatures. These features make polyolefin-based separators the primary choice for battery manufacturers. Despite such remarkable characteristics, polyolefin-based separators still suffer from some vital limitations that lead to poor electrochemical properties. These disadvantages include low porosity, electrolyte uptake, and inferior thermal stability [19-22]. To counteract the above-mentioned issues associated with the commercialized separators, there is a need to prepare highly porous polymer membranes that have good affinity towards liquid electrolytes and act as a gel polymer electrolyte (GPE) once impregnated with liquid electrolytes. Owing to the combined characteristics of solid and liquid electrolytes, these GPEs have displayed an improved ionic conductivity in the order of $10^{-3} \mathrm{~S} / \mathrm{cm}$ while providing better safety to the lithium ion battery [23,24]. Poly(vinyl alcohol) (PVA) [25], poly(vinylidene fluoride) (PVDF) [26,27], polyacrylonitrile (PAN) [28,29], poly(methyl methacrylate) (PMMA) [30], and poly(vinylidene fluoride-hexafluropropylene) (PVDF-HFP) [31,32] are the polymer host materials primarily employed in the preparation of the GPE. PAN has some interesting features that assist it in qualifying as a good choice for preparing porous polymer membranes. Owing to the presence of a polar cyano group, PAN facilitates better transport of lithium ions. Apart from that, the stability of PAN in terms of its electrochemical and thermal behavior is sufficient. Additionally, it also does not react with the electrolytes used in the battery. In fact, PAN displays better gelation characteristics once it comes in contact with the liquid electrolyte due to the enhanced electrolyte uptake of the PAN-based membrane [33-35].

The introduction of ceramic materials into the polymer matrix can lead to some extraordinary characteristics owing to the mixed benefits of the two different types of materials and assists in enhancing the mechanical and thermal behaviors of the pristine polymer. Apart from that, the electrochemical features of the polymer membrane are also improved with the addition of ceramics into the polymer matrix due to the greater compatibility with the electrodes [36-38]. Among the different available ceramic materials, lithium aluminum titanium phosphate (LATP) has been often exploited as a solid state electrolyte owing to its high ionic conductivity of approximately $10^{-4} \mathrm{~S} / \mathrm{cm}$ [39]. The improved ionic conductivity of the LATP particles can be attributed to the 3D interlocking network established due to the unique structure of LATP [40]. The polymer-LATP composite has been previously investigated as a composite electrolyte. Forsyth et al. used LATP as an additive to the polymer salt matrix of polyurethane and lithium triflate to observe how the polymer-ceramic interaction influenced the conductivity of the electrolytes [41]. In another work, Mao et al. utilized the solvent casting technique to design a PVDF-LATP composite electrolyte for application in solid-state lithium ion batteries. Enhanced electrochemical features have been previously displayed by the PVDF-LATP composite electrolyte [42]. The application of PAN-LATP composites as separators for lithium ion batteries has been studied by Zhang et al. They prepared PAN-based membranes with different concentrations of LATP, i.e., 5, 10, and $15 \mathrm{wt} \%$. They observed an enhancement in the electrochemical properties of the coin cell, with a separator of $15 \mathrm{wt} \%$ PAN-LATP showing the best features [43]. As the $15 \mathrm{wt} \%$ sample displayed superior properties, it will be interesting to study how a higher concentration of LATP affects PAN-LATP membranes (PL membranes). Hence, in this work, an electrospinning technique was employed to prepare PL membranes with higher concentrations of LATP (i.e., 30 and $50 \mathrm{wt} \%$ ). A thorough analysis of these PL membranes was performed through various structural, physical, and electrochemical characterizations. The synthesized PL membranes exhibit improved porosity and electrolyte uptake, better thermal stability, and enhanced electrochemical features, which makes them promising as separators for lithium ion batteries. 


\section{Materials and Methods}

\subsection{Fabrication of PL Membranes}

Polyacrylonitrile (MW 20000) was obtained from Polysciences, Inc. (Warrington, PA, USA). Dimethylformamide (DMF) and N-Butanol were procured from Daejung Chemicals and Metals Co. Ltd. (Siheung-Si, South Korea). Electrolyte $1 \mathrm{M} \mathrm{LiPF}_{6}$ in EC/DMC = 50/50 (v/v) was borrowed from Sigma Aldrich (St. Louis, MO, United States).

LATP was synthesized using a simple sol-gel method, as reported earlier by one of the authors [44]. For the fabrication of the PL membranes, first a $6 \mathrm{wt} \%$ PAN solution was prepared using DMF as the solvent. To this solution, different $w \mathrm{t} \%$ s of LATP (30 and $50 \mathrm{wt} \%$ ) were incorporated and allowed to stir at $60{ }^{\circ} \mathrm{C}$ until the LATP became completely soluble in the PAN matrix, followed by ultrasonication to prepare a homogeneous solution for electrospinning. Adopting the same procedure, PL membranes with 0 and LATP $10 \mathrm{wt} \%$ were prepared to report a complete trend of the PL membranes with various characteristics. A $10 \mathrm{~mL}$ volume of the prepared polymeric solution was removed with a syringe with a bore size 19 needle for electrospinning in a NanoNC electrospinning/spray system containing a rotating drum collector covered with aluminum foil. The voltage, flow rate, and distance between the needle and sample collector were $18 \mathrm{kV}, 3 \mathrm{~mL} / \mathrm{h}$, and $15 \mathrm{~cm}$, respectively. After the electrospinning process was completed, the sample was peeled from the aluminum foil and cut into spheres of $14 \mathrm{~mm}$ in diameter followed by drying in vacuum oven at $60^{\circ} \mathrm{C}$ for $24 \mathrm{~h}$ to obtain PL membranes with thicknesses varying from 36 to $45 \mu \mathrm{m}$. The samples with different weight \% of LATP were denoted as P-L0, P-L10, P-L30, and P-L50 for $0,10,30$, and $50 \mathrm{wt} \%$, respectively.

\subsection{Characterization of PL Membranes}

To study the morphology of the prepared PL membranes, the PL membranes were first coated with platinum, followed by field emission scattering electron microscopy (FESEM) of the membranes with a Jeol JSM-7610F (Tokyo, Japan). XRD study was done with RigakuSmartLab 3 (Tokyo, Japan) to determine the alteration in the crystallinity of the membranes with the incorporation of various weight $\%$ of LATP, whereas the Fourier transform infrared (FT-IR) spectra of the PL membranes was performed with an Agilent Cary 670. Thermogravimetric analysis of the PL membranes was performed using SETARAM instrumentation (LABSYS EVO TGA) (Caluire, France) in a nitrogen atmosphere at a scan rate of $10{ }^{\circ} \mathrm{C} / \mathrm{min}$ to report the thermal stability of the membranes. The N-butanol soak up method was used to report the variation in porosity of the PL membranes. This method involved measuring the weight of the membranes before and after soaking them in n-butanol for two hours. After that, the following formula was employed to calculate the porosity of the PL membranes:

$$
\text { Porosity }(\%)=\left(\mathrm{W}_{\text {wet }} / \rho_{\mathrm{b}}\right) /\left\{\left(\mathrm{W}_{\text {wet }} / \rho_{\mathrm{b}}\right)+\left(\mathrm{W}_{\mathrm{dry}} / \rho_{\mathrm{s}}\right)\right\} \times 100 \%
$$

where $\mathrm{W}_{\text {wet }}=$ weight of membranes after soaking in $\mathrm{n}$ - butanol, $\mathrm{W}_{\text {dry }}=$ weight of membranes before soaking in $\mathrm{n}$-butanol, $\mathrm{V}_{\mathrm{dry}}=$ Volume of membrane, $\rho_{\mathrm{b}}=$ Density of $\mathrm{n}$-butanol, and $\rho_{\mathrm{s}}=$ Density of separator.

To determine the electrolyte uptake of the PL membranes, the membranes were left in the dissolved liquid electrolyte, i.e., LiPF6 in EC/DMC, for up to two hours. Then, the initial and final weights of membranes after electrolyte submersion were determined, which were then used in the following equation to obtain the electrolyte uptake of the PL membranes:

$$
\text { Electrolyte Uptake }(\%)=\left\{\left(\mathrm{W}_{\text {wet }}-\mathrm{W}_{\text {dry }}\right) / \mathrm{W}_{\mathrm{dry}}\right\} \times 100 \%
$$

where $W_{\text {wet }}=$ weight of membranes after soaking in liquid electrolyte and $W_{\text {dry }}=$ weight of membranes before soaking in liquid electrolyte.

A Nyquist impedance plot was created with the help of a Zive SP2 Electrochemical workstation (Seoul, South Korea). First, the membranes were soaked with electrolyte and then kept between 
the Swagelok cells for the impedance measurement, which used a frequency range of $1 \mathrm{~Hz}-1 \mathrm{MHz}$. The Nyquist plot provided the bulk resistance with which the ionic conductivity of the membranes was calculated by employing the following equation:

$$
\sigma=\left(1 / R_{b}\right) \times(1 / A)
$$

where $\sigma$ is the ionic conductivity, $R_{b}$ is the bulk resistance, 1 is the thickness of membrane, and $A$ is the area of the membrane.

\subsection{Electrochemical Characterization}

Charge-discharge studies and the cyclic voltammetry measurements of the membranes were carried out by preparing coin cells using lithium metal foil, lithium iron phosphate $\left(\mathrm{LiFePO}_{4}\right), \mathrm{and} \mathrm{LiPF}_{6}$ in EC-DMC as the anode, cathode, and electrolyte, respectively. These studies were conducted with a universal battery tester with a voltage range of $2.5 \mathrm{~V}$ to $4.2 \mathrm{~V}$. $\mathrm{LiFePO}_{4}, \mathrm{PVdF}$, and super $\mathrm{P}$ were employed with a ratio of 8:1:1 to prepare the $\mathrm{LiFePO}_{4}$ cathode in the presence of $\mathrm{N}$-methyl pyrrolidone solvent. The active mass loading of the cathode was calculated to be approximately $5 \mathrm{mg} / \mathrm{cm}^{2}$.

\section{Results and Discussion}

\subsection{Morphology and Phase Change of PL Membranes}

PL membranes with varied LATP concentrations were prepared employing the facile electrospinning technique. The fabrication process is shown in Figure 1. Stirring for a long period of time followed by ultrasonication results in better homogeneity of the PL membranes. To observe the change in the morphology of the electrospun PL membranes with different amount of LATP, FESEM microscopy of the PL membranes was carried out. Figure 2 displays the FESEM micrograph of the PL membranes. The usage of the electrospinning technique assists in the formation of well aligned fibrous PL membranes, as indicated in the FESEM images. The formation of fibrous PL membranes gives rise to an improved porosity, which is shown in Table 1 . The diameters of the pristine PAN fibrous membrane are found to be in the 130-260 $\mathrm{nm}$ range. With the incorporation of LATP particles into the PAN matrix, the polymer solution becomes more viscous than the pristine PAN solution, which results in the increase in the fiber diameters of the electrospun PL membranes. A similar increase in the fiber diameters of a $\mathrm{P}(\mathrm{VdF}-\mathrm{TrFE})$ membrane from the introduction of $\mathrm{Al}_{2} \mathrm{O}_{3}$ nanoparticles has also been previously reported [45]. An increase in the viscosity with the addition of LATP particles is a major reason that it was not possible to fabricate PL membranes with higher than $50 \mathrm{wt} \% \mathrm{LATP}$. In P-L50 itself there is large amount of variation in the fiber diameters, as seen in Figure $2 \mathrm{~d}$, due to a greater accumulation of LATP particles, which leads the of P-L50 membrane demonstrating inferior properties when compared to P-L30 (Table 1). To report the successful inclusion of LATP ceramic particles within the PAN polymer matrix, EDS of the PL membranes was also performed using the FESEM. The presence of titanium and aluminum are seen in the EDS of the PL membranes (Figure S1), indicating fruitful incorporation of the LATP particles. The virgin PAN membrane displays only carbon and nitrogen peaks due to the nitrile group, whereas the platinum peaks in each of the PL membranes are the result of the platinum coating of the PL membranes prior to FESEM analysis. To have a clearer picture of presence of ceramic particles in PAN matrix, elemental mapping of P-L30 has been done and displayed in Figure S2. It displays all the components of PAN and LATP except the lighter element lithium. 

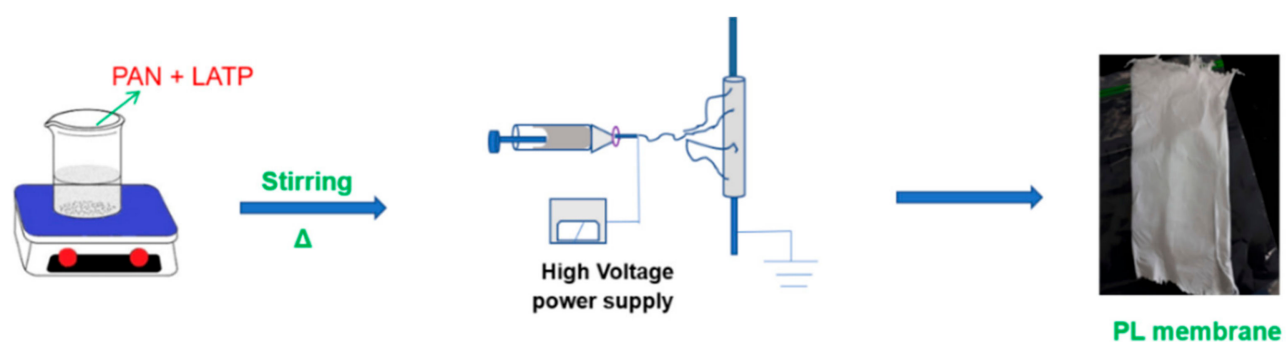

Electrospinning Process

PL membrane

Figure 1. Preparation process of polyacrylonitrile (PAN)-lithium aluminum titanium phosphate (LATP) membranes (PL membranes).
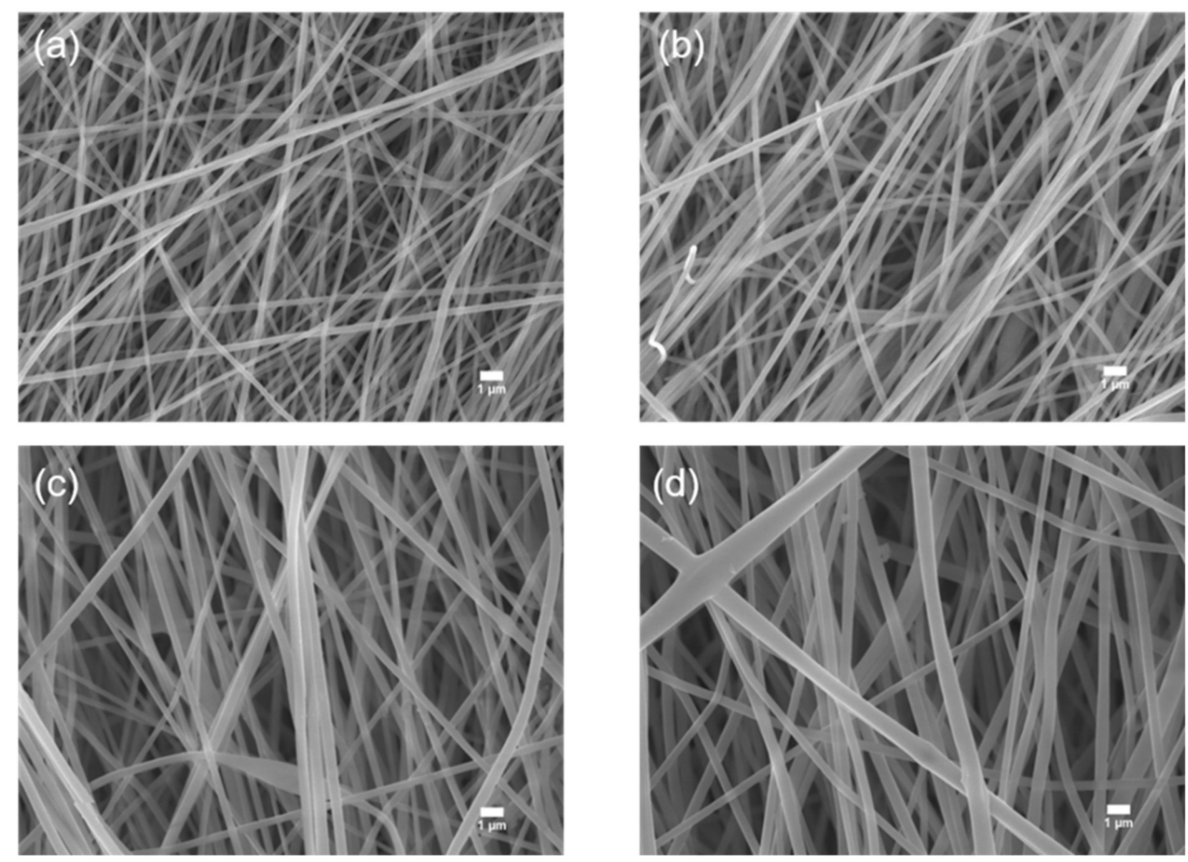

Figure 2. Field emission scattering electron microscopy (FESEM) of (a) P-L0; (b) P-L10; (c) P-L30; and (d) P-L50.

Table 1. Porosity, electrolyte uptake, and ionic conductivity values of PL membranes.

\begin{tabular}{cccc}
\hline Sample & Porosity (\%) & Electrolyte Uptake (\%) & Ionic Conductivity (mS/cm) \\
\hline P-L0 & 66.7 & 325 & 0.22 \\
P-L10 & 83.3 & 525 & 1.4 \\
P-L30 & 90 & 600 & 1.7 \\
P-L50 & 76 & 400 & 0.89 \\
\hline
\end{tabular}

Furthermore, XRD and FT-IR were carried out to demonstrate the interaction between the two moieties that constitute the PL membranes viz. PAN and LATP. The XRD plot shown in Figure 3a displays a characteristic peak at approximately $17^{\circ}$ for a pristine PAN membrane [46]. Due to the crystalline characteristics of LATP, characteristic crystalline peaks of LATP start to appear alongside the peak of the pristine PAN membrane with the increase of the LATP weight \%, indicating the efficacious insertion of LATP particles inside the PAN matrix. The increase in peaks upon the addition of LATP denotes the gradual transition from the polymeric to ceramic phase. P-L50 displays more crystalline LATP peaks when compared to other membranes due to presence of a higher amount of LATP. The high crystallinity of P-L50 leads to its poor electrochemical performance when compared to the P-L30 membrane, as described in Figure 5. The fine amalgamation of different moieties in the separator is very important for the electrochemical performance of the separators. FT-IR is a useful 
tool for demonstrating the mixing of PAN and LATP through the changes in the functional group peaks. Figure $3 \mathrm{~b}$ shows the FT-IR of the PL membranes. The characteristic nitrile group peak for PAN is observed around $2240 \mathrm{~cm}^{-1}$, and the $-\mathrm{CH}_{2}$ stretching and bending peaks are observed around 2900 and $1400 \mathrm{~cm}^{-1}$, respectively. A decrease in the intensity of these peaks in the PL membranes with addition of LATP particles demonstrates the good mixing of the LATP particles within the PAN matrix. Recently, Lei et al. observed a similar type of reduction in the intensities of the FT-IR peaks of PVDF-based membranes when LATP ceramic particles were introduced into them, and ascribed it to the alteration of the PVDF bonds due to complexation between the ceramic LATP particles and PVDF [47].
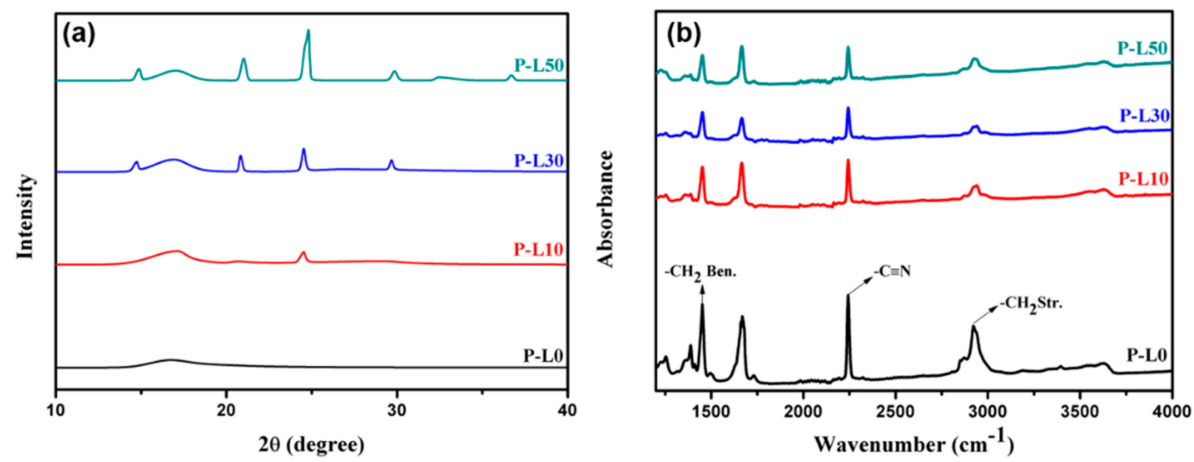

Figure 3. (a) XRD and (b) Fourier transform infrared (FT-IR) spectra of PL membranes.

\subsection{Porosity, Electrolyte Uptake, Thermal Stability, and Ionic Conductivity of PL Membranes}

Porosity is a vital criterion for battery separators, as the ability to absorb the liquid electrolyte efficiently eventually assists in achieving better electrochemical features [11]. The porosity of the PL membranes is shown in Figure 4a. The pure PAN membrane displays a porosity of approximately $67 \%$. With the addition of LATP particles, the porosity of the PL membranes increases, as shown in Table 1. The enhancement in porosity with the addition of LATP particles can be ascribed to the increased fiber diameters [35]. The highest porosity is observed using the P-L30 membrane, i.e., 90\%, after which a reduction in porosity is observed for the P-L50 membrane. This can be ascribed to the greater disparity in the fiber diameters in P-L50, as evident from the FESEM results. The improved porosity of the membranes results in a better ability to retain the electrolyte and hence a superior electrochemical performance [48].

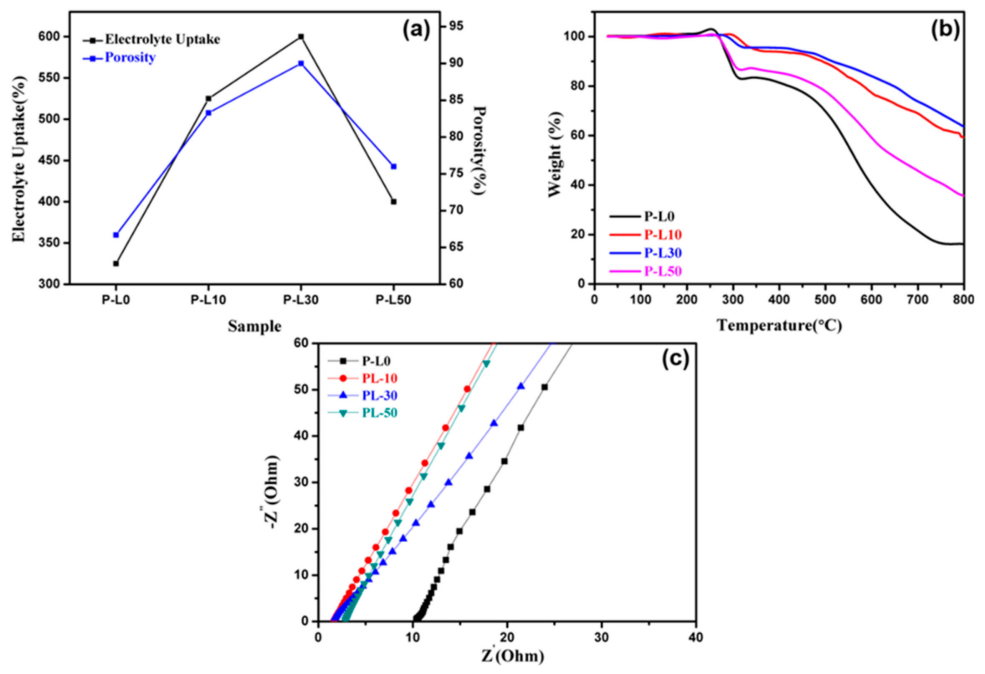

Figure 4. (a) Porosity and electrolyte uptake; (b) Thermogravimetric Analysis (TGA); and (c) Nyquist impedance plot of PL membranes. 
All the PL membranes have higher porosity than that of separators (42\%) employed for commercial lithium ion batteries. The electrospinning process used for PL membrane preparation in this work results in better fibrous structures with interconnected networks that in turn result in the improved porosity of the PL membranes [49]. The porosities of some reported PAN-based membranes are shown in Table 2. It is clearly visible from Table 2 that the porosity of the P-L30 membrane is the highest when compared to previously reported PAN-based membranes. The improved porosity leads to better electrochemical characteristics of the membrane [50]. The enhanced porosity is vital for the application of the membrane as a separator for lithium ion batteries, but has an adverse effect on the mechanical strength of the membranes [10,51]. The extreme stress experienced by the PL membranes was found to be approximately $10 \mathrm{MPa}$, i.e., for P-L30, as shown in Figure S3. When compared to commercialized polyethylene membranes, the tensile strength is lower but the membrane still has enough mechanical sturdiness to be employed as a separator for lithium ion batteries.

The electrolyte uptake heavily relies on the porosity, because a higher porosity enhances the interfacial contact between the electrolyte and the separator [52]. Hence, the electrolyte uptake values for PL membranes show a trend similar to the porosity trend viz. P-L0 < P-L10 < P-L30 > P-L50. Table 1 displays the electrolyte uptake values of the PL membranes. As compared to the pristine PAN membrane, P-L10 with $10 \mathrm{wt} \%$ LATP shows better electrolyte uptake, which increases further with P-L30, giving a maximum electrolyte uptake value of $600 \%$. The enhanced electrolyte uptake and porosity of the P-L30 membrane improves the lithium insertion and extraction during the charge-discharge cycle and hence results in better cyclic stability [50]. However, increasing the LATP concentration to $50 \mathrm{wt} \%$ leads to a reduction in the electrolyte uptake owing to a greater aggregation of LATP in the polymer matrix. Recently, Thomas et al. described similar electrolyte uptake behavior in which, with an increase in the amount of $\mathrm{Al}_{2} \mathrm{O}_{3}$, the electrolyte uptake of a $\mathrm{P}(\mathrm{VdF}-\mathrm{TrFE})$ membrane increases but, in case of an even higher quantity of $\mathrm{Al}_{2} \mathrm{O}_{3}$, the electrolyte uptake values decreased [45].

Table 2. Porosity of PAN-based membranes.

\begin{tabular}{ccc}
\hline PAN Based Separator Works & Porosity (\%) & Reference \\
\hline Electrospun PAN membranes & 68 & {$[53]$} \\
$\mathrm{SiO}_{2} / \mathrm{PAN}$ & 77 & {$[54]$} \\
$\mathrm{Lignin}_{\mathrm{PAN}}$ & 74 & {$[35]$} \\
PAN/PI & 87 & {$[50]$} \\
PAN-LATP (P-L30) & 90 & This Work \\
\hline
\end{tabular}

Another major concern for separators is thermal stability. The safety of the battery depends on the improved thermal stability of the separator. Highly thermally stable separators can resist high temperatures and can avert shrinkage at elevated temperatures, which impacts the performance of the lithium ion battery. The thermal stability of the PL membranes was investigated through the TGA measurements depicted in Figure $4 b$, in which the samples were exposed to a temperature range starting from room temperature to $800^{\circ} \mathrm{C}$ at a scan rate of $10^{\circ} \mathrm{C} / \mathrm{min}$. A major weight loss occurs between $290{ }^{\circ} \mathrm{C}$ and $300^{\circ} \mathrm{C}$ due to the melting of the polymer host, i.e., PAN, after which no major weight loss occurs, and only the membrane decomposes. Still, after $800{ }^{\circ} \mathrm{C}$, the residual weight percents of the PL membranes are $16 \%, 59 \%, 63 \%$, and 35\% for P-L0, P-L10, P-L30, and P-L50, respectively, whereas a reduction in weight of more than $90 \%$ is observed in the case of commercially used polyethylene and polypropylene separators by $600^{\circ} \mathrm{C}[55,56]$. The enhanced residual weight $\%$ of PL membranes compared to commercial polypropylene separator and pristine PAN membrane, i.e., P-L0, can be ascribed to the fine thermal properties of the added LATP particles [47]. As is evident, the P-L30 membrane is more thermally stable when compared to the other samples, indicating that the P-L30 membrane is the best sample from the lot, which is also well corroborated by the porosity and electrolyte uptake results. Additionally, digital images of the celgard separator and P-L30 membrane are depicted in Figure S4 before and after heat treatment at $170{ }^{\circ} \mathrm{C}$ for $1 \mathrm{~h}$. After $1 \mathrm{~h}$, the celgard 
separator was completely melted down, whereas in case of P-L30 the color changed from white to yellow but there was little thermal shrinkage ( 14\%) of P-L30 membrane, indicating the enhanced thermal stability of PL membrane compared to commercial celgard separator.

Figure 4c shows the Nyquist impedance plots of the PL membranes soaked in liquid electrolyte, i.e., LiPF6 in EC-DMC. The point at which the curves of the PL membranes touch the real impedance axis is considered to be the bulk resistance, $\mathrm{Rb}$, of the membranes. Taking $\mathrm{Rb}$, the ionic conductivity of the membranes was determined using Equation (3). The calculated ionic conductivity values are listed in Table 1. The P-L0 membrane, i.e., the membrane without LATP, demonstrated an ionic conductivity of $0.22 \mathrm{mS} / \mathrm{cm}$, but increases in ionic conductivity values have been observed in the incorporation of LATP into the membrane, which can be ascribed to the higher ionic conductivity of the LATP particles [40,43]. The ionic conductivity values of P-L10, P-L30, and P-L50 are $1.4 \mathrm{mS} / \mathrm{cm}, 1.7 \mathrm{mS} / \mathrm{cm}$, and $0.89 \mathrm{mS} / \mathrm{cm}$, respectively. The enhanced electrolyte uptake and porosity of the P-L30 membrane improves its ionic conductivity above all the other PL membranes [57,58]. The improved ionic conductivity of P-L30 membrane is further corroborated through the cyclic voltammetry measurements (Figure S5), in which the difference between the anodic and cathodic peak is found to be the lowest when using the P-L30 membrane (i.e., $293 \mathrm{mV}$ ), indicating high lithium ion transportation in the P-L30 case. More aggregation of ceramic particles gives rise to less electrolyte uptake of P-L50, which leads to display of low ionic conductivity of P-L50 compared to P-L10 and P-L30.

\subsection{Electrochemical Investigation of PL Membranes}

To test the efficiency of the PL membranes for use in a lithium ion battery, the PL membranes were assembled in coin cells with a lithium metal anode and a LIFePO4 cathode, using LiPF6 in EC-DMC as the liquid electrolyte. The initial charge-discharge profiles of the cells with PL membranes are displayed in Figure 5a. It can be observed that cells with a pristine PAN membrane without any LATP have a discharge capacity of approximately $134 \mathrm{mAh} / \mathrm{g}$ at $0.5 \mathrm{C}$ rate, which improves with the inclusion of LATP. A $30 \mathrm{wt} \%$ inclusion shows the highest discharge capacity at $158 \mathrm{mAh} / \mathrm{g}$. The elevated ionic conductivity of the P-L30 membrane results in the improved charge-discharge behavior of the coin cell with the P-L30 membrane and hence overall results in the improved capacity of the coin cell [59]. Due to a reduction in porosity and electrolyte uptake, the coin cell with PL membrane with $50 \mathrm{wt} \%$ LATP shows a reduced capacity when compared to the coin cell with a P-L30 membrane. The charge-discharge curves of the Celgard separator at $0.5 \mathrm{C}$ rate are also included with the charge-discharge curves PL membranes, and it can be seen that there is very little difference in the specific capacity value between the coin cells with a Celgard separator and with only a PAN membrane, but the capacity of a coin cell with the Celgard separator is much lower when compared to coin cells with LATP containing PL membranes. The enhanced capacity of the PL membranes can be ascribed to the better electrolyte retaining ability, which comes from their fibrous structure. This result demonstrates that PL membranes containing LATP could be a better option than commercial separators.

Figure $5 \mathrm{~b}$ shows the rate capability of the PL membranes by varying the C-rate from $0.5 \mathrm{C}$ to 4C. Due to the lithium insertion/extraction mechanism of the LIFePO4 cathode, a reduction in the discharge capacities of the PL membranes is observed as the C-Rate increases [60]. Still, the P-L30 membrane maintains $56 \%$ of its initial capacity at a rate of $4 \mathrm{C}$, whereas the capacity retention of P-L0, P-L10, and P-L50 is 26\%, 49\%, and 39\%, respectively. This indicates that the high electrolyte uptake of the P-L30 membrane contributes to efficient lithium ion intercalation and deintercalation, even at a rate of 4 C. All the PL membranes display efficacious reversibility, as the capacity shows little change when the rate returns from $4 \mathrm{C}$ to a smaller $\mathrm{C}$ rate, i.e., $0.5 \mathrm{C}$. The greater reversibility of the PL membranes can be ascribed to the homogeneous mixing of the LATP within the polymer matrix, as evident from the FTIR studies [61]. 

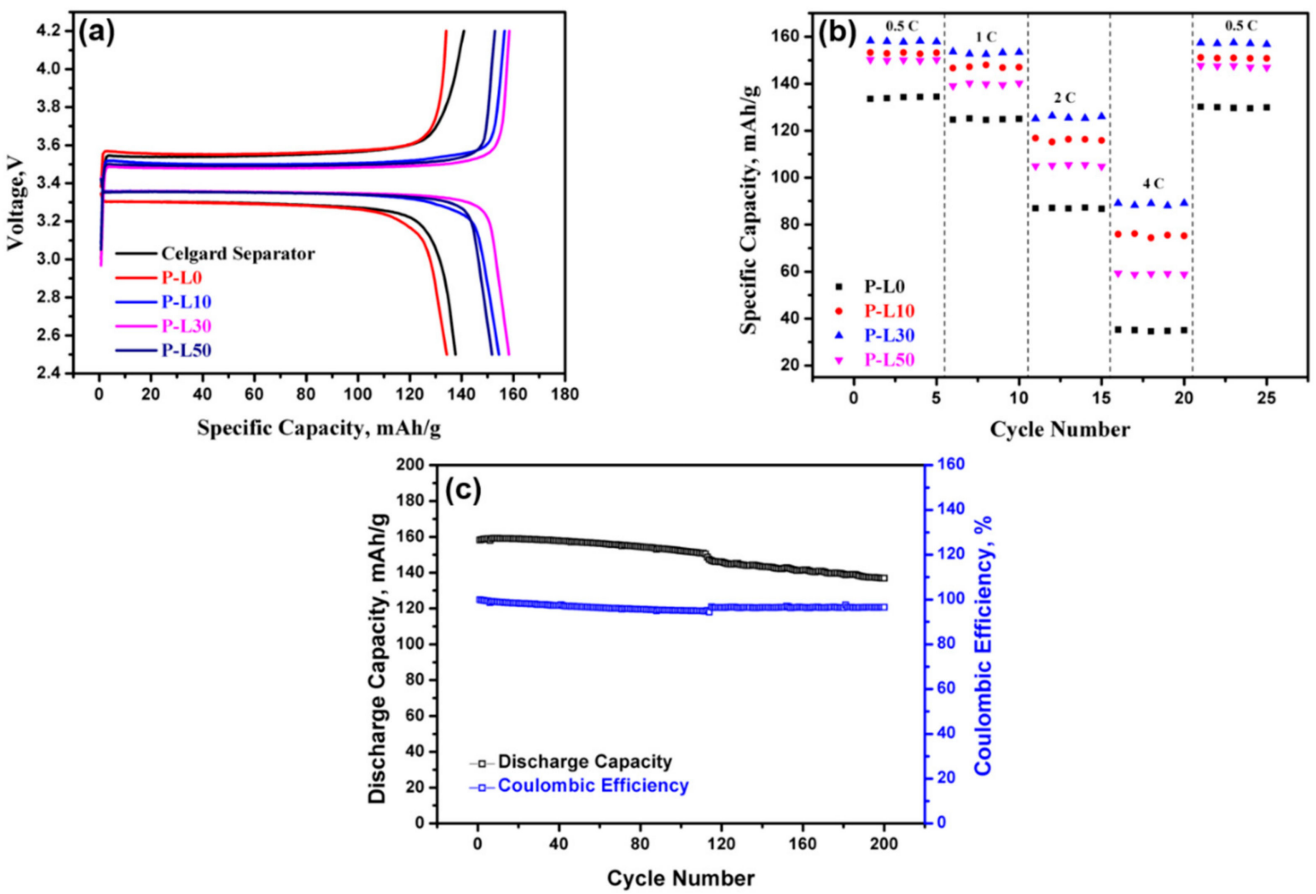

Figure 5. (a) Initial charge-discharge curve with 0.5C rate of PL membranes, (b) rate capability of PL membranes, and (c) cyclic stability and efficiency of P-L30.

Since the coin cell with the P-L30 membrane displays the highest discharge capacity, the long-term stability of the P-L30 membrane for use in a lithium ion battery was tested. This was performed by measuring the cycling performance of P-L30 membrane containing coin cell at a $0.5 \mathrm{C}$ rate for 200 cycles, shown in Figure 5c. It was found that even after undergoing 200 charge-discharge cycles, the coin cell using the P-L30 membrane retained $87 \%$ of its initial discharge capacity. The enhanced cycling stability of the coin cell with the PL-30 membrane can be attributed to higher porosity of the P-L30 membrane, which restricts the evolution of lithium dendrites during repeated cycling [62]. Further, the enhanced electrolyte uptake and increased ionic conductivity also plays a crucial role in the cycling stability of the P-L30 membrane. Figure S6 displays the FESEM image of the P-L30 membrane after undergoing 200 cycles of charge and discharge. Even after 200 cycles, there is no major changes in the fiber diameters; only deposition of particles was observed between the fibers, which may have been due to the LFP cathode. Such type of particle deposit was also observed by Lee et al. in the PE separators after undergoing 100 cycles of charge and discharge [63]. The coulombic efficiency changes of the coin cell containing the P-L30 membrane are also displayed in Figure $5 \mathrm{c}$. The initial charge-discharge cycle at a rate of $0.5 \mathrm{C}$ shows a coulombic efficiency of $99.93 \%$, and after 200 cycles, it still maintains a high coulombic efficiency of $96.5 \%$, indicating the efficacy of using the P-L30 membrane as a lithium ion battery separator.

\section{Conclusions}

An electrospinning procedure has been employed to prepare PAN-based membranes with high concentrations of LATP particles, i.e., 30 and $50 \mathrm{wt} \%$. To have a complete variation trend demonstrating different properties, membranes with 0 and $10 \mathrm{wt} \%$ were also prepared. The FESEM results showed that the pure PAN membrane was a well-aligned fibrous membrane, but upon increasing the LATP concentration, irregularities in the fiber diameters were noticed. XRD and FT-IR measurements showed the fine interaction between the PAN and LATP particles. Due to a higher porosity, the P-L30 membrane displayed improved characteristics such as better electrolyte uptake, greater thermal stability, and an augmented ionic conductivity of $1.7 \mathrm{mS} / \mathrm{cm}$, results that were superior to those of the other PL membranes tested. LiFePO4/Li-based coin cells prepared with a P-L30 membrane exhibited 
an enhanced discharge capacity of $158 \mathrm{mAh} / \mathrm{g}$ at $0.5 \mathrm{C}$ rate and displayed good capacity retention with a higher C-rate. Furthermore, only a $13 \%$ reduction in the capacity was observed while cycling the coin cell with the P-L30 membrane for 200 cycles at a $0.5 \mathrm{C}$ rate, and an improved coulombic efficiency of $96.5 \%$ was retained after charging and discharging the P-L30-based coin cell for 200 cycles at a rate of $0.5 \mathrm{C}$. Hence, the prepared PL membranes are promising candidates for lithium ion battery applications.

Supplementary Materials: The following are available online at http://www.mdpi.com/2079-4991/9/11/1581/s1, Figure S1: EDS of PL Membranes; Figure S2: Elemental Mapping of P-L30; Figure S3: Stress-Strain curves of PL membranes; Figure S4: Heat treatment at $170{ }^{\circ} \mathrm{C}$ of (a) P-L30 (b) celgard separator (Above - Before Heat treatment; Below-After Heat treatment); Figure S5: Cyclic Voltammetry of PL membranes; Figure S6: FESEM image of P-L30 membrane after 200 cycles of Charge and discharge.

Author Contributions: Conceptualization, J.M. and J.-K.K.; Investigation, J.M., O.H.K. and J.H.C.; Writing-Original Draft Preparation, J.M.; Writing-Review and Editing, J.M., J.-K.K., S.M.J. and Y.-M.Y.; Supervision J.K.K. and S.M.J.

Funding: This research was funded by the Basic Science Research Program through the National Research Foundation of Korea (NRF) funded by the Ministry of Education (2017M1A2A2087577 and 2018R1A4A1024691).

Conflicts of Interest: The authors declare no conflict of interest. The funders had no role in the design of the study; in the collection, analyses, or interpretation of data; in the writing of the manuscript; or in the decision to publish the results.

\section{References}

1. Feng, X.; Ouyang, M.; Liu, X.; Lu, L.; Xia, Y.; He, X. Thermal runaway mechanism of lithium ion battery for electric vehicles: A review. Energy Storage Mater. 2018, 10, 246-267. [CrossRef]

2. Li, M.; Lu, J.; Chen, Z.; Amine, K. 30 years of lithium-ion batteries. Adv. Mater. 2018, 30, 1800561. [CrossRef] [PubMed]

3. Liu, K.; Liu, Y.; Lin, D.; Pei, A.; Cui, Y. Materials for lithium-ion battery safety. Sci. Adv. 2018, 4, eaas9820. [CrossRef]

4. Feng, K.; Li, M.; Liu, W.; Kashkooli, A.G.; Xiao, X.; Cai, M.; Chen, Z. Silicon-based anodes for lithium-ion batteries: From fundamentals to practical applications. Small 2018, 14, 1702737. [CrossRef] [PubMed]

5. Liang, G.; Qin, X.; Zou, J.; Luo, L.; Wang, Y.; Wu, M.; Zhu, H.; Chen, G.; Kang, F.; Li, B. Electrosprayed silicon-embedded porous carbon microspheres as lithium-ion battery anodes with exceptional rate capacities. Carbon 2018, 127, 424-431. [CrossRef]

6. Ko, H.S.; Park, H.W.; Kim, G.J.; Lee, J.D. Electrochemical characteristics of lithium-excess cathode material $\left(\mathrm{Li}_{1+x} \mathrm{Ni}_{0.9} \mathrm{Co}_{0.05} \mathrm{Ti}_{0.05} \mathrm{O}_{2}\right)$ for lithium-ion batteries. Korean J. Chem. Eng. 2019, 36, 620-624. [CrossRef]

7. Kim, S.C.; Park, Y.K.; Kim, B.H.; Kim, H.; Lee, W.J.; Lee, H.; Jung, S.C. Facile precipitation of tin oxide nanoparticles on graphene sheet by liquid phase plasma method for enhanced electrochemical properties. Korean J. Chem. Eng. 2018, 35, 750-756. [CrossRef]

8. Choi, S.I.; Lee, Y.M.; Jeong, H.C.; Jung, E.J.; Lee, M.S.; Kim, J.; Kim, Y.H.; Won, Y.S. Preparation of Si/C anode with PVA nanocomposite for Lithium-ion battery using electrospinning method. Korean Chem. Eng. Res. 2018, 56, 139-142.

9. Kim, Y.S.; Oh, S.Y.; Kim, E.; Kim, D.; Kim, S.; Chu, C.H.; Park, K. Iron-Chrome crossover through Nafion membrane in Iron-Chrome redox flow battery. Korean Chem. Eng. Res. 2018, 56, 24-28.

10. Costa, C.M.; Kundu, M.; Dias, J.C.; Nunes-Pereira, J.; Botelho, G.; Silva, M.M.; Lanceros-Méndez, S. Mesoporous poly (vinylidene fluoride-co-trifluoroethylene) membranes for lithium-ion battery separators. Electrochim. Acta 2019, 301, 97-106. [CrossRef]

11. Costa, C.M.; Kundu, M.; Cardoso, V.F.; Machado, A.V.; Silva, M.M.; Lanceros-Méndez, S. Silica/poly (vinylidene fluoride) porous composite membranes for lithium-ion battery separators. J. Membr. Sci. 2018, 564, 842-851. [CrossRef]

12. Guo, T.; Song, J.; Jin, Y.; Sun, Z.; Li, L. Thermally stable and green cellulose-based composites strengthened by styrene-co-acrylate latex for lithium-ion battery separators. Carbohydr. Polym. 2019, 206, 801-810. [CrossRef] [PubMed]

13. Lagadec, M.F.; Zahn, R.; Wood, V. Characterization and performance evaluation of lithium-ion battery separators. Nat. Energy 2019, 4, 16-25. [CrossRef] 
14. Yan, S.; Deng, J.; Bae, C.; Xiao, X. Thermal expansion/shrinkage measurement of battery separators using a dynamic mechanical analyzer. Polym. Test. 2018, 71, 65-71. [CrossRef]

15. Zhang, T.W.; Tian, T.; Shen, B.; Song, Y.H.; Yao, H.B. Recent advances on biopolymer fiber based membranes for lithium-ion battery separators. Compos. Commun. 2019, 14, 7-14. [CrossRef]

16. Wang, E.; Wu, H.P.; Chiu, C.H.; Chou, P.H. The effect of battery separator properties on thermal ramp, overcharge and short circuiting of rechargeable Li-Ion batteries. J. Electrochem. Soc. 2019, 166, A125-A131. [CrossRef]

17. Costa, C.M.; Silva, M.M.; Lanceros-Méndez, S. Battery separators based on vinylidene fluoride (VDF) polymers and copolymers for lithium ion battery applications. RSC Adv. 2013, 3, 11404-11417. [CrossRef]

18. Yoon, K.; Hsiao, B.S.; Chu, B. Functional nanofibers for environmental applications. J. Mater. Chem. 2008, 18, 5326-5334. [CrossRef]

19. Li, J.; Zhong, Q.; Yao, Y.; Bi, S.; Zhou, T.; Guo, X.; Wu, M.; Feng, T.; Xiang, R. Electrochemical performance and thermal stability of the electrospun PTFE nanofiber separator for lithium-ion batteries. J. Appl. Polym. Sci. 2018, 135, 46508. [CrossRef]

20. Feng, G.; Li, Z.; Mi, L.; Zheng, J.; Feng, X.; Chen, W. Polypropylene/hydrophobic-silica-aerogel-composite separator induced enhanced safety and low polarization for lithium-ion batteries. J. Power Sources 2018, 376, 177-183. [CrossRef]

21. Pan, R.; Cheung, O.; Wang, Z.; Tammela, P.; Huo, J.; Lindh, J.; Edström, K.; Strømme, M.; Nyholm, L. Mesoporous Cladophora cellulose separators for lithium-ion batteries. J. Power Sources 2016, 321, 185-192. [CrossRef]

22. Rao, E.; McVerry, B.; Borenstein, A.; Anderson, M.; Jordan, R.S.; Kaner, R.B. Roll-to-roll functionalization of polyolefin separators for high-performance lithium-ion batteries. ACS Appl. Energy Mater. 2018, 1, 3292-3300. [CrossRef]

23. Stephan, A.M. Review on gel polymer electrolytes for lithium batteries. Eur. Polym. J. 2006, 42, 21-42. [CrossRef]

24. Liu, B.; Huang, Y.; Cao, H.; Zhao, L.; Huang, Y.; Song, A.; Lin, Y.; Wang, M.; Li, X. A novel polyacrylonitrile-based porous structure gel polymer electrolyte composited by incorporating polyhedral oligomeric silsesquioxane by phase inversion method. J. Solid State Electrochem. 2018, 22, 1771-1783. [CrossRef]

25. Subramania, A.; Sundaram, N.K.; Kumar, G.V.; Vasudevan, T. New polymer electrolyte based on (PVA-PAN) blend for Li-ion battery applications. Ionics 2006, 12, 175-178. [CrossRef]

26. Liu, L.; Wang, Z.; Zhao, Z.; Zhao, Y.; Li, F.; Yang, L. PVDF/PAN/SiO 2 polymer electrolyte membrane prepared by combination of phase inversion and chemical reaction method for lithium ion batteries. J. Solid State Electrochem. 2016, 20, 699-712. [CrossRef]

27. Li, H.; Chao, C.Y.; Han, P.L.; Yan, X.R.; Zhang, H.H. Preparation and properties of gel-filled PVDF separators for lithium ion cells. J. Appl. Polym. Sci. 2017, 134, 44473. [CrossRef]

28. Almuhamed, S.; Bonne, M.; Khenoussi, N.; Brendle, J.; Schacher, L.; Lebeau, B.; Adolphe, D.C. Electrospinning composite nanofibers of polyacrylonitrile/synthetic Na-montmorillonite. J. Ind. Eng. Chem. 2016, 35, 146-152. [CrossRef]

29. Huai, Y.; Gao, J.; Deng, Z.; Suo, J. Preparation and characterization of a special structural poly (acrylonitrile)-based microporous membrane for lithium-ion batteries. Ionics 2010, 16, 603-611. [CrossRef]

30. Vondrák, J.; Sedlaríková, M.; Reiter, J.; Kašpar, D. PMMA Based Gel Polymer Electrolytes. In Materials for Lithium-Ion Batteries; Julien, C., Stoynov, Z., Eds.; Springer: Dordrecht, The Netherlands, 2000.

31. He, J.; Liu, J.; Li, J.; Lai, Y.; Wu, X. Enhanced ionic conductivity and electrochemical capacity of lithium ion battery based on PVDF-HFP/HDPE membrane. Mater. Lett. 2016, 170, 126-129. [CrossRef]

32. Kang, D.W.; Kim, J.K. Characterization of fibrous gel polymer electrolyte for lithium polymer batteries with enhanced electrochemical properties. J. Electroanal. Chem. 2016, 775, 37-42. [CrossRef]

33. Elia, G.A.; Ducros, J.B.; Sotta, D.; Delhorbe, V.; Brun, A.; Marquardt, K.; Hahn, R. Polyacrylonitrile separator for high-performance aluminum batteries with improved interface stability. ACS Appl. Mater. Interfaces 2017, 9, 38381-38389. [CrossRef] [PubMed]

34. Ma, X.; Kolla, P.; Yang, R.; Wang, Z.; Zhao, Y.; Smirnova, A.L.; Fong, H. Electrospun polyacrylonitrile nanofibrous membranes with varied fiber diameters and different membrane porosities as lithium-ion battery separators. Electrochim. Acta 2017, 236, 417-423. [CrossRef] 
35. Zhao, M.; Wang, J.; Chong, C.; Yu, X.; Wang, L.; Shi, Z. An electrospun lignin/polyacrylonitrile nonwoven composite separator with high porosity and thermal stability for lithium-ion batteries. RSC Adv. 2015, 5, 101115-101120. [CrossRef]

36. Freitag, A.; Langklotz, U.; Rost, A.; Stamm, M.; Ionov, L. Ionically conductive polymer/ceramic separator for lithium-sulfur batteries. Energy Storage Mater. 2017, 9, 105-111. [CrossRef]

37. Kumar, J.; Kichambare, P.; Rai, A.K.; Bhattacharya, R.; Rodrigues, S.; Subramanyam, G. A high performance ceramic-polymer separator for lithium batteries. J. Power Sources 2016, 301, 194-198. [CrossRef]

38. Kim, K.W.; Kim, H.W.; Kim, Y.; Kim, J.K. Composite gel polymer electrolyte with ceramic particles for $\mathrm{LiNi}_{1 / 3} \mathrm{Mn}_{1 / 3} \mathrm{Co}_{1 / 3} \mathrm{O}_{2}-\mathrm{Li}_{4} \mathrm{Ti}_{5} \mathrm{O}_{12}$ lithium ion batteries. Electrochim. Acta 2017, 236, 394-398. [CrossRef]

39. Duluard, S.; Paillassa, A.; Puech, L.; Vinatier, P.; Turq, V.; Rozier, P.; Lenormand, P.; Taberna, P.L.; Simon, P.; Ansart, F. Lithium conducting solid electrolyte $\mathrm{Li}_{1.3} \mathrm{Al}_{0.3} \mathrm{Ti}_{1.7}\left(\mathrm{PO}_{4}\right)_{3}$ obtained via solution chemistry. J. Eur. Ceram. Soc. 2013, 33, 1145-1153. [CrossRef]

40. Kou, Z.; Miao, C.; Wang, Z.; Mei, P.; Zhang, Y.; Yan, X.; Jiang, Y.; Xiao, W. Enhanced ionic conductivity of novel composite polymer electrolytes with $\mathrm{Li}_{1.3} \mathrm{Al}_{0.3} \mathrm{Ti}_{1.7}\left(\mathrm{PO}_{4}\right)_{3}$ NASICON-type fast ion conductor powders. Solid State Ion. 2019, 338, 138-143. [CrossRef]

41. Nairn, K.M.; Best, A.S.; Newman, P.J.; Macfarlane, D.R.; Forsyth, M. Ceramic-polymer interface in composite electrolytes of lithium aluminium titanium phosphate and polyetherurethane polymer electrolyte. Solid State Ion. 1999, 121, 115-119. [CrossRef]

42. Liang, X.; Han, D.; Wang, Y.; Lan, L.; Mao, J. Preparation and performance study of a PVDF-LATP ceramic composite polymer electrolyte membrane for solid-state batteries. RSC Adv. 2018, 8, 40498-40504. [CrossRef]

43. Liang, Y.; Lin, Z.; Qiu, Y.; Zhang, X. Fabrication and characterization of LATP/PAN composite fiber-based lithium-ion battery separators. Electrochim. Acta 2011, 56, 6474-6480. [CrossRef]

44. Lee, S.S.; Lim, Y.J.; Kim, H.W.; Kim, J.K.; Jung, Y.G.; Kim, Y. Electrochemical properties of a ceramic-polymer-composite-solid electrolyte for Li-ion batteries. Solid State Ion. 2016, 284, 20-24. [CrossRef]

45. Bicy, K.; Suriyakumar, S.; Anu, A.S.; Kalarikkal, N.; Stephen, A.M.; Geethamma, V.G.; Rouxel, D.; Thomas, S. Highly lithium ion conductive, $\mathrm{Al}_{2} \mathrm{O}_{3}$ decorated electrospun $\mathrm{P}(\mathrm{VDF}-\mathrm{TrFE})$ membranes for lithium ion battery separators. New J. Chem. 2018, 42, 19505-19520.

46. Sigwadi, R.; Dhlamini, M.S.; Mokrani, T.; Nemavhola, F. Structural morphology and electronic conductivity of blended Nafion@-polyacrylonitrile/zirconium phosphate nanofibres. Int. J. Mech. Mater. Eng. 2019, 14. Available online: https://link.springer.com/article/10.1186/s40712-019-0098-1 (accessed on 7 November 2019). [CrossRef]

47. Shi, X.; Ma, N.; Wu, Y.; Lu, Y.; Xiao, Q.; Li, Z.; Lei, G. Fabrication and electrochemical properties of LATP/PVDF composite electrolytes for rechargeable lithium-ion battery. Solid State Ion. 2018, 325, 112-119. [CrossRef]

48. Jiang, L.; Zhang, X.; Chen, Y.; Qiao, L.; Lu, X.; Tian, X. Modified polypropylene/cotton fiber composite nonwoven as lithium-ion battery separator. Mater. Chem. Phys. 2018, 219, 368-375. [CrossRef]

49. Zhao, H.; Deng, N.; Yan, J.; Kang, W.; Ju, J.; Wang, L.; Li, Z.; Cheng, B. Effect of OctaphenylPolyhedral oligomeric silsesquioxane on the electrospun Poly-m-phenylene isophthalamid separators for lithium-ion batteries with high safety and excellent electrochemical performance. Chem. Eng. J. 2019, 356, 11-21. [CrossRef]

50. Li, L.; Liu, P.; Fu, Q.S.; Gong, Y.; Zhang, S.R.; He, H.J.; Chen, J. Study on preparation of polyacrylonitrile/polyimide composite lithium-ion battery separator by electrospinning. J. Mater. Res. 2019, 34, 642-651. [CrossRef]

51. Li, D.; Zhang, H.; Li, X. Porous polyetherimide membranes with tunable morphology for lithium-ion battery. J. Membr. Sci. 2018, 565, 42-49. [CrossRef]

52. Waqas, M.; Ali, S.; Lv, W.; Chen, D.; Boateng, B.; He, W. High-Performance PE-BN/PVDF-HFP bilayer separator for lithium-ion batteries. Adv. Mater. Interfaces 2019, 6, 1801330. [CrossRef]

53. Arifeen, W.U.; Kim, M.; Choi, J.; Yoo, K.; Kurniawan, R.; Ko, T.J. Optimization of porosity and tensile strength of electrospun polyacrylonitrile nanofibrous membranes. Mater. Chem. Phys. 2019, 229, 310-318. [CrossRef]

54. Yanilmaz, M.; Lu, Y.; Zhu, J.; Zhang, X. Silica/polyacrylonitrile hybrid nanofiber membrane separators via sol-gel and electrospinning techniques for lithium-ion batteries. J. Power Sources 2016, 313, $205-212$. [CrossRef]

55. Zhang, Y.; Wang, Z.; Xiang, H.; Shi, P.; Wang, H. A thin inorganic composite separator for lithium-ion batteries. J. Membr. Sci. 2016, 509, 19-26. [CrossRef] 
56. Chao, C.Y.; Feng, Y.F.; Hua, K.; Li, H.; Wu, L.J.; Zhou, Y.S.; Dong, Z.W. Enhanced wettability and thermal stability of polypropylene separators by organic-inorganic coating layer for lithium-ion batteries. J. Appl. Polym. Sci. 2018, 135, 46478. [CrossRef]

57. Sun, G.; Dong, G.; Kong, L.; Yan, X.; Tian, G.; Qi, S.; Wu, D. Robust polyimide nanofibrous membrane with porous-layer-coated morphology by in situ self-bonding and micro-crosslinking for lithium-ion battery separator. Nanoscale 2018, 10, 22439-22447. [CrossRef]

58. Kong, L.; Yan, Y.; Qiu, Z.; Zhou, Z.; Hu, J. Robust fluorinated polyimide nanofibers membrane for high-performance lithium-ion batteries. J. Membr. Sci. 2018, 549, 321-331. [CrossRef]

59. Yanilmaz, M.; Zhang, X. Polymethylmethacrylate/polyacrylonitrile membranes via centrifugal spinning as separator in Li-ion batteries. Polymers 2015, 7, 629-643. [CrossRef]

60. Xu, H.; Li, D.; Liu, Y.; Jiang, Y.; Li, F.; Xue, B. Preparation of halloysite/polyvinylidene fluoride composite membrane by phase inversion method for lithium ion battery. J. Alloy Compd. 2019, 790, 305-315. [CrossRef]

61. Liu, M.; Zhang, P.; Gou, L.; Hou, Z.; Huang, B. Enhancement on the thermostability and wettability of lithium-ion batteries separator via surface chemical modification. Mater. Lett. 2017, 208, 98-101. [CrossRef]

62. Ma, L.; Chen, R.; Hu, Y.; Zhang, W.; Zhu, G.; Zhao, P.; Chen, T.; Wang, C.; Yan, W.; Wang, Y.; et al. Nanoporous and lyophilic battery separator from regenerated eggshell membrane with effective suppression of dendritic lithium growth. Energy Storage Mater. 2018, 14, 258-266. [CrossRef]

63. Lee, H.; Lim, H.S.; Ren, X.; Yu, L.; Engelhard, M.H.; Han, K.S.; Lee, J.; Kim, H.T.; Xiao, J.; Liu, J.; et al. Detrimental effects of chemical crossover from the lithium anode to cathode in rechargeable lithium metal batteries. ACS Energy Lett. 2018, 3, 2921-2930. [CrossRef]

(C) 2019 by the authors. Licensee MDPI, Basel, Switzerland. This article is an open access article distributed under the terms and conditions of the Creative Commons Attribution (CC BY) license (http://creativecommons.org/licenses/by/4.0/). 